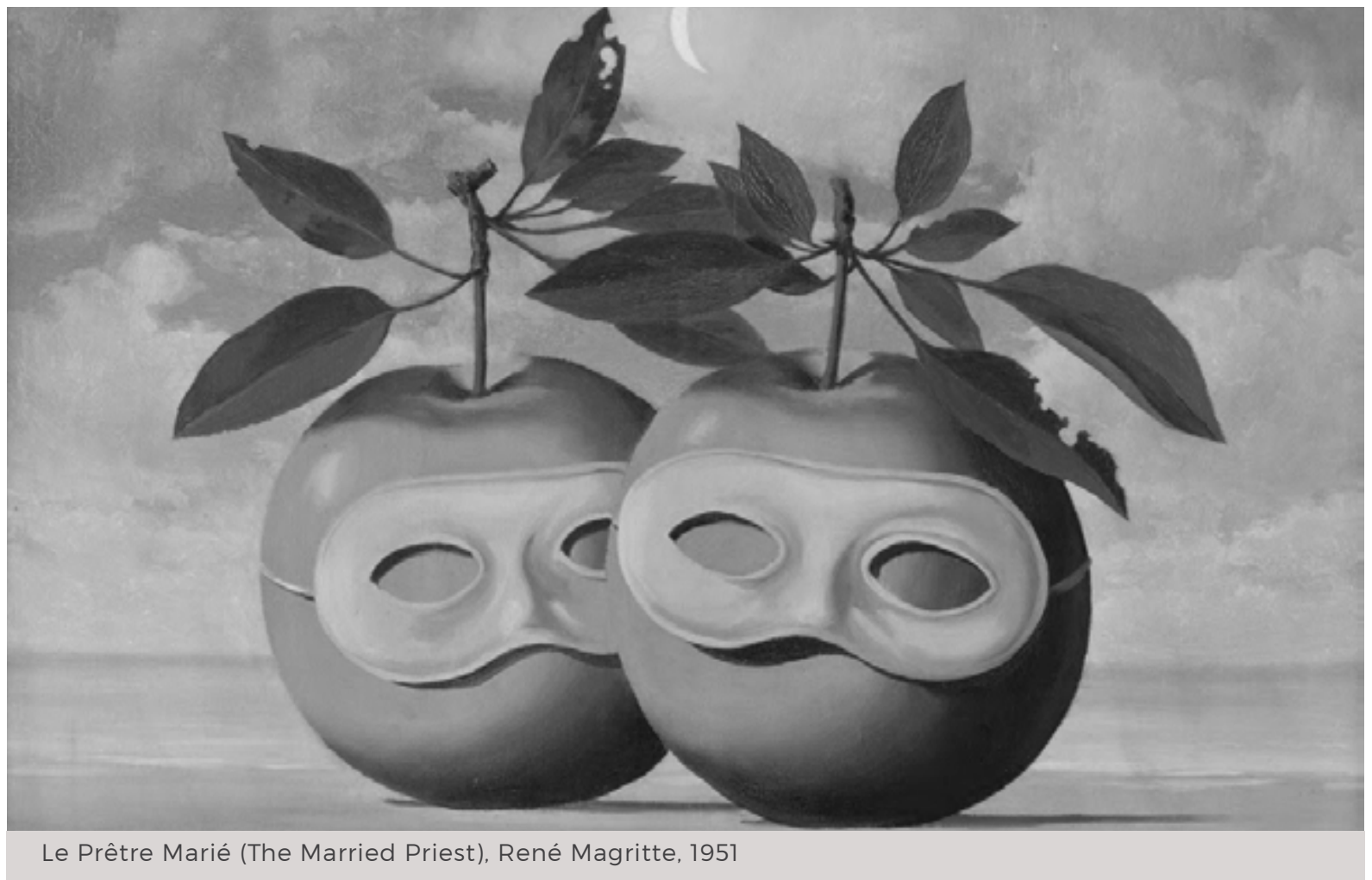

\section{Treating What Ails the Study of Chinese Politics}

\section{William Hurst}

For almost as long as political science has existed as a discipline, the study of Chinese politics has been afflicted with a chronic disease. Depending on one's perspective, this malady's manifestations have amounted to either neglected isolation or arrogant exceptionalism. To treat this illness, it is important to set aside any rigid orthodoxy and to encourage and celebrate diversity and bold experimentation.
For almost as long as political science has existed as a discipline, the study of Chinese politics has been afflicted with a chronic disease. Depending on one's perspective, this malady's manifestations have amounted to either neglected isolation or arrogant exceptionalism. At root has been a tendency of China scholars to recount everything they could learn about one village or neighbourhood, one leader, or one army group, without context or comparison, assuming the wider world would care simply because their research was about China; and then the wider world took little notice. Regardless of whom one believes may have been to blame, students of Chinese politics have been searching for curative remedies for at least the past fortyfive years.

During the 1970 s and 1980 s, it was en vogue to deploy macro-models of Chinese politics, both to compensate for our field's relative data paucity and to make findings more readily intelligible to non-area specialists. Even when such models had names like 
'Mao in Command', they still represented first attempts to 'replace proper names with variables'. Yet, just as the last of these olderstyle model debates was raging (between proponents of 'civil society' and 'corporatism' perspectives), a number of scholars sought to introduce greater methodological rigor and better demonstrate the validity of their findings by making use of dramatically more advanced survey techniques and quantitative analysis than had ever before been common in the China field. From about 1990-2005, this trend did indeed bring some greater visibility to at least some parts of the field, though it began to bump up against some limits of data availability, research costs, and political strictures and risks. Survey research remains important, but it proved not to be a panacea.

Roughly contemporaneously, from around 1995-2010, some other scholars (including this writer) tried to make the study of Chinese politics more systematic, accurate, and ultimately generalisable by advocating for a new emphasis on subnational comparative analysis within China. Whether they compared regions, elements of the bureaucracy, social groups, or even time periods, these colleagues hoped that stepby-step disaggregation and more careful attention to China's internal diversity might refine the specification of hypothesised causal processes and mechanisms and enable testable claims about their scope of generalisability. As with the survey tradition, this had the potential to allow concepts and theories to travel more readily, not only into China from other parts of comparative politics but also in the opposite direction. Yet, Chinese politics never became anything close to a net exporter of theory or concepts during this period.

\section{Racing for a Cure}

Faced with the ongoing relative otiosity of prior therapies, alongside the stress of an ever more competitive and vagarious job market, a new generation of students has gravitated toward a different approach-one that is predicated on a sea change in the China field. Over more or less the past decade, Chinese politics has gone from a data-poor field to one overflowing with all manner of observable phenomena that can be examined, counted, aggregated, or analysed. In part, this has been driven by a technological revolution in both the output of content and techniques for 'scraping' or otherwise 'mining' it, allowing the endless torrent of terabytes produced by and for the Internet to be converted into useful sets of 'big data'. In part, it has also been based on other innovations, such as the use of field experiments and a greater propensity than among most of their predecessors for today's graduate students and junior scholars to collaborate closely with leading quantitative researchers based in Mainland China. The preferred regimen of the new generation is thus to play in what could be called the discipline's methods arms race, deploying ever more stunning technical tools and operations in hopes of impressing the discipline as a supreme virtuoso after the current fashion (or fad), outshining all others, landing a good job, and then making one's mark.

Yet, while the shiny object so many are reaching for may be a brass ring, it is no silver chalice. Today's younger scholars are certainly landing jobs, but the Holy Grail of bringing Chinese politics into the core of political science remains elusive and the concentration and compression of new research into increasingly small-bore methodological debates and frameworks risks the perverse effect of rendering the field even more marginal and less relevant. At its worst, scholarship in the new mould can amount merely to taking up concepts or hypotheses uncritically from American politics or haphazard corners of comparative politics and testing them out with bigger and bigger Chinese datasets and fancier and fancier 
methods. Such research can end up asking the wrong questions, cutting itself out of the most essential conversations even before it has settled on findings. All of the current emphasis, for example, on discerning through experiments how mayors or other local officials in China's consultative authoritarian system respond to claims from different social groups has produced some impressive, even virtuosic, articles. But all such work is predicated on the assumption that China's is indeed a consultative authoritarian system. of course, the really important question is whether consultative authoritarianism describes China very well at all (I do not think it does, but I would welcome a healthy debate). The obsessive focus on methods occludes the fact that a great deal of research can be misguided (and thus at best trivial and at worst wrong) from the get-go. Unfortunately, if such work predominates, Chinese politics can appear from the outside as mundane, epiphenomenal, or even vapidly irrelevant. China specialists are relegated still further toward the edges of the discipline, even as they loose their area studies moorings, and slowly drift toward abject obscurity.

Even at its very best, embracing the methods arms race constitutes but one candidate sanative treatment. The mad dash toward it since about 2010, however, has left other potential contenders neglected. There are many other ways we might bring the study of China's rich historical experience, internal diversity, unique institutional landscape, and dynamic economy and society into conversation with the rest of political science. It is high time we pay attention to one of these: cross-national comparative analysis.

\section{Cross-National Comparison: A Refreshing Therapy}

When I speak of cross-national comparison, I do not mean the type that was popular several decades ago and sometimes amounted to throwing hundreds of country-case (or even worse country-year) scores into a statistical package and seeing which broad claims might stick (e.g.: democracies do not fight, unions strike less under left-leaning governments, etc.). Rather, I wish to advocate for careful paired comparison of China with other individual countries or small sets of countries. Combining this with careful, historically and contextually informed, work on China's domestic politics-whether quantitative, qualitative, subnationally comparative, or other-has the potential to let us export ideas and arguments at least as well as brandishing the latest technical tools to test others' hypotheses.

Broadly speaking, there are four ways to undertake the kind of cross-national work I am advocating. I call them: shadows, mirrors, partners, and apples. I have listed these in increasing order of both their risks and difficulty and of their potential dividends. Shadow comparisons are the sort that one finds in the concluding chapters of old books-not only the ones about China, but also many with titles like 'XXX's Party System in Comparative Perspective'. After offering the reader a study of politics in a single country (e.g. China), authors would pad a last chapter full of vignettes about how the arguments might be applied to another country or set of countries, almost always based entirely on a very superficial reading of a thin set of secondary sources. This is not useless (I have done it), but it is of limited utility. Still, it remains all too rare in the writing of China specialists. Mirror comparisons involve a much more nuanced look at one or two countries that in some important way reflect China's political reality as analysed or explained in the main body of a work. This might involve at least a chapter or two, also likely (but not necessarily) drawn from secondary sources, that delve into considerable detail to examine how causal processes and mechanisms uncovered in the 
rest of a book play out in a critical case or set of cases for testing whether they might travel beyond China's borders. This has become popular in recent work on India and other large countries, but has remained largely unexploited by students of Chinese politics. More common in studies of international relations, partner comparisons revolve around the study of China's relationships with a particular other country or set of countries (e.g. Japan or the Soviet Union). Such comparisons usually become the main focus of the books based on them and often (but not always) can require relatively in-depth and extensive, though tightly focused, fieldwork and/or primary source research in a country other than China. Apples comparisons carry by far the highest costs and risks, but also the greatest potential rewards.

In an apples comparison, a researcher endeavours to compare China and some other country (or set of countries) side-by-side as co-equal units; that is, to compare 'apples to apples'. Doing so in a way that remains faithful to the immense internal diversity and complexity of politics in China requires nothing short of training up fully in the language, history, and politics of another country (or multiple other countries), to at least a roughly similar level of expertise that the researcher had acquired on the China case. This means many years of language study, at least a small library's worth of reading, and even more time spent on the ground in the field in a new country. There is thus little chance that any single scholar can cultivate more than one or a very small number of apples to compare with China during his or her career. Apple comparisons can be tricky and are often complicated by uneven access to data, vastly divergent political strictures or economic contexts, or the absence of key actors or events in either China or the apple comparator; furthermore, not every apple will be suitable for comparison with China on all possible research questions or areas. Nevertheless, investment in developing apple comparisons can be incredibly fruitful. Such a method enables one to deploy mostsimilar and most-different systems designs simultaneously (one within each case and the other between), for example, to compare subnational units or phenomena across national boundaries, and to test the limits and scope of generalisability not only in terms of broad causal arguments but also very precisely of specific causal mechanisms. Concepts developed to characterise elements of Chinese politics can be refined in the full light of another case before being offered as wares for export to a broader comparative politics audience.

\section{Comparing China with Southeast Asia: A Modest Proposal}

When China scholars have attempted comparisons-of any of the four types just discussed-they have often selected India or Russia as comparators. These are certainly not bad choices, but they are difficult in important ways and lacking in a certain kind of comparative advantage. With secondary literatures and area studies scholarly traditions as vast or even larger than those on China, Russia and India require an especially large amount of upfront investment to get up to speed. Research on these countries has also tended to favour a similar sort of disaggregation, close-tothe-ground fieldwork, and a 'splitting' (as opposed to 'lumping') approach to that which has classically characterised much work on Chinese politics. In this, they lack any comparative advantage that might be conferred by having strengths complementary to the China field's. Thus, adding new innovation or knowledge through comparative analysis is particularly difficult. Though one could certainly look elsewhere (from Mongolia to Mexico) with excellent results, I propose that many countries of Southeast Asia (Myanmar, 
Thailand, Cambodia, Laos, Vietnam, the Philippines, Indonesia, and Malaysia) can be especially apt comparator cases for the kinds of cross-national work on China I am advocating.

The study of politics (as opposed to culture, history, or society) in Southeast Asia has suffered from an opposite pathology to that which has plagued the China field. Rather than assuming the wider field would care about their findings because they were rooted in the study of Southeast Asian countries, specialists on that part of the world have too often tended to assume the field would never care about their findings because they were derived from the study of Southeast Asia. This has led a lot of scholarship to focus tightly on what is generalisable or exportable about Southeast Asian countries' experiences or outcomes, rather than what is unique; never to miss the forest for the trees, but often to emphasise the broad shape of the landscape without even naming the tree species present. In sum, Southeast Asian politics offers a comparative advantage as a comparator area because it has focused on exactly the areas the China field has neglected or been weak in and has tended too often to neglect exactly the areas (e.g.: local variation, subnational politics, etc.) on which the China field has done well. Also, none of the countries of Southeast Asia have area studies or secondary literatures of similar volume to those associated with Russia or India (indeed, other than those on Vietnam, Thailand, the Philippines, and Indonesia, secondary literatures on Southeast Asian countries' politics and history are comparatively quite small). The costs are thus relatively low, the comparative advantages obvious, and the payoffs potentially very high for using Southeast Asian countries as comparison cases to bring the study of Chinese politics into closer dialogue with the rest of political science. I very much hope more students and colleagues will heed this call to consider delving into these and other country cases seriously for this purpose.

\section{All Hands Needed on Deck}

To conclude, I do not intend this essay to be any sort of definitive or final statement. Rather, I hope it may spark important conversations. I am more than happy to be corrected or invited to rethink any and all aspects of what I have said here. My greatest aspiration is to motivate colleagues and students to think more expansively and daringly about what is possible and desirable in terms of Chinese politics research. There is nothing wrong with technical sophistication in one's methods and there is absolutely a rightful place for research using 'big data', experiments, and other new tools. But we must prevent the stifling homogeneity of the methods arms race from becoming completely ensconced and crowding out all other work (especially by younger or emerging scholars). Diversity and bold experimentation must win out over any rigid orthodoxy if we have any chance to put our patient's illness fully into remission.

\section{William Hurst}

William Hurst is Associate Professor of Political Science at Northwestern University, where his work focuses on dimensions of Chinese and Indonesian politics including: political economy, social movements and contentious politics, labour politics, and the politics of law and legal institutions. $\mathrm{He}$ is the author of The Chinese Worker after Socialism (Cambridge 2009) and Ruling Before the Law: The Politics of Legal Regimes in China and Indonesia (Cambridge 2018, forthcoming). 